\title{
Effects of cadmium perturbation on the microbial community structure and heavy metal resistome of a tropical agricultural soil
}

\author{
Lateef B. Salam ${ }^{1 *}$ (D) Oluwafemi S. Obayori ${ }^{2}$, Mathew O. Ilori ${ }^{3}$ and Olukayode O. Amund ${ }^{3}$
}

\begin{abstract}
The effects of cadmium (Cd) contamination on the microbial community structure, soil physicochemistry and heavy metal resistome of a tropical agricultural soil were evaluated in field-moist soil microcosms. A Cd-contaminated agricultural soil (SL5) and an untreated control (SL4) were compared over a period of 5 weeks. Analysis of the physicochemical properties and heavy metals content of the two microcosms revealed a statistically significant decrease in value of the soil physicochemical parameters $(P<0.05)$ and concentration of heavy metals $(\mathrm{Cd}, \mathrm{Pb}, \mathrm{Cr}, \mathrm{Zn}, \mathrm{Fe}, \mathrm{Cu}, \mathrm{Se})$ content of the agricultural soil in SL5 microcosm. Illumina shotgun sequencing of the DNA extracted from the two microcosms showed the predominance of the phyla, classes, genera and species of Proteobacteria (37.38\%), Actinobacteria (35.02\%), Prevotella (6.93\%), and Conexibacter woesei (8.93\%) in SL4, and Proteobacteria (50.50\%), Alphaproteobacteria (22.28\%), Methylobacterium (9.14\%), and Methylobacterium radiotolerans (12,80\%) in SL5, respectively. Statistically significant $(P<0.05)$ difference between the metagenomes was observed at genus and species delineations. Functional annotation of the two metagenomes revealed diverse heavy metal resistome for the uptake, transport, efflux and detoxification of various heavy metals. It also revealed the exclusive detection in SL5 metagenome of members of RND (resistance nodulation division) protein czcCBA efflux system ( $c z c A, c z r A, c z r B$ ), CDF (cation diffusion facilitator) transporters ( $C z C D$ ), and genes for enzymes that protect the microbial cells against cadmium stress (sodA, $\operatorname{sod} B$, ahpC). The results obtained in this study showed that $\mathrm{Cd}$ contamination significantly affects the soil microbial community structure and function, modifies the heavy metal resistome, alters the soil physicochemistry and results in massive loss of some autochthonous members of the community not adapted to the $\mathrm{Cd}$ stress.
\end{abstract}

Keywords: Cadmium, Agricultural soil, Heavy metals, Soil microcosm, Shotgun metagenomics, Microbial community structure and function, Heavy metal resistome

\section{Introduction}

Cadmium $(\mathrm{Cd})$ is a highly toxic, carcinogenic heavy metal with an exceptionally high biological half-life ( $>20$ years) and propensity for accumulation in the food chain, drinking water and soil (Benavides et al. 2005; Khan et al. 2015; Fashola et al. 2016). Major sources of $\mathrm{Cd}$ in soil include

\footnotetext{
*Correspondence: babssalaam@yahoo.com

${ }^{1}$ Department of Biological Sciences, Microbiology Unit, Summit

University, Offa, Kwara, Nigeria

Full list of author information is available at the end of the article
}

wet and dry atmospheric deposition (vehicular emission, incineration, burned fuel and tyre wear, residual ashes from wood, coal or other types of combustion) (Mielke et al. 1991; Steinnes and Friedland 2006); and geological weathering (Khan et al. 2010; Liu et al. 2013). Other primary anthropogenic sources of $\mathrm{Cd}$ in soil include mining, sewage sludge, composted municipal solid wastes, improper waste disposal practices, smelting, wastewater irrigation, manufacturing and agrochemicals (Alloway 
and Steinnes 1999; Khan et al. 2016a, b; Nawab et al. 2016; Khan et al. 2017).

Elevated $\mathrm{Cd}$ concentration in soil poses significant threat to the quantity and diversity of soil microorganisms. Cd toxicity to microbial cells is believed to be due to depletion of glutathione and sulfhydryl groups in proteins, interaction with nucleic acids, oxidative damage by production of reactive oxygen species, and inactivation of metalloproteins due to displacement of $\mathrm{Zn}$ and Fe ions (Vallee and Ulmer 1972; Stohs and Bagchi 1995; Fortuniak et al. 1996; Stohs et al. 2001; Banjerdkij et al. 2005). This result in protein denaturation, cell membrane and nucleic acid disruption, and inhibition of transcription, cell division and enzyme activities (Fashola et al. 2016). Several workers have also highlighted the debilitating effects of $\mathrm{Cd}$ toxicity on the lung, kidney, bones, and the nervous and immune systems of humans (Adriano 2001; Waisberg et al. 2003; Edwards and Prozialeck 2009; Yazdankhah et al. 2010; Satarug et al. 2001; Moynihan et al. 2017). Furthermore, Cd cytotoxicity has been implicated in destruction of plant mitochondria as well as disruption of photosynthesis and transpiration (Imai and Siegel 1973; Toppi and Gabbrielli 1999; Lopez-Milla'n et al. 2009; Mohamed et al. 2012; Júnior et al. 2014; Khan et al. 2016a, b).

Bioremediation of $\mathrm{Cd}$-inundated soil is predicated on the presence of highly efficient Cd uptake/transport/ efflux/detoxification system within the soil microbial community well-adapted to $\mathrm{Cd}$ stress. Mechanisms such as intracellular or extracellular precipitation, active efflux, and transformation to less toxic species have been used by microorganisms to counteract heavy metal stress (Nies 1999, 2003; Hu et al. 2005). In Cd resistance, three families of efflux transporters are deployed by microorganisms. They are the P-type ATPases, which traverse the inner membrane and use ATP energy to pump metal ions from the cytoplasm (Nucifora et al. 1989; Rensing et al. 1997); the CBA (capsule biogenesis assembly) transporters, which act as cation-proton antiporters (Nies and Silver 1989; Nies 1995; Hassan et al. 1999); and the cation diffusion facilitator (CDF) transporters, which act as chemiosmotic ion-proton exchanger (Xiong and Jayaswal 1998; Anton et al. 1999; Grass et al. 2001; Nies 2003).

Previous works have deployed culture-based and culture-independent methods to monitor the effects of heavy metal contamination on autochthonous soil microbial community. In most cases, where culture-independent approach was used, specific resistance genes are amplified via PCR techniques (Rhee et al. 2004; Bhadra et al. 2005; Altimira et al. 2012). Information obtained from such studies cannot be adapted to design effective bioremediation strategies as it does not reflect the true picture of heavy metal resistome in such environments.
The use of shotgun metagenomics allows deep metagenomic sequencing providing unprecedented insight into the genetic potentials of microbial communities as well as underrepresented populations (Handelsman 2004; Oulas et al. 2015). It also reveals the communal nature of microbial existence and the interplay between diverse genes and processes produced and marshalled by members of the microbial community to counteract various environmental stressors. This exciting approach have been used to decipher the microbial community structure and function of diverse polluted and pristine soils (Salam et al. 2017, 2018; Feng et al. 2018; Salam et al. 2019).

In recent time, attempts have been made to use nextgeneration shotgun metagenomics to characterize the microbial community structure and function of heavy metal-inundated soils. However, to the best of our knowledge, none of the reports have used the approach to extensively decipher the specific resistance systems deployed by members of the microbial community to counteract the stress imposed by the studied heavy metal. Here, we report the use of shotgun metagenomics to decipher the effects of $\mathrm{Cd}$ contamination on the microbial community structure and heavy metal resistome of a tropical agricultural soil.

\section{Materials and methods}

\section{Sampling site description}

Soil samples were collected from an agricultural farm in Ilorin, Kwara State, Nigeria. The coordinates of the sampling site were latitude $8^{\circ} 27^{\prime} 45.36^{\prime \prime} \mathrm{N}$ and longitude $4^{\circ}$ $32^{\prime} 7.08^{\prime \prime}$ E. Historically, farming at the sampling site dated back to $10-15$ years and crops such as maize, cassava, cocoyam, beans and guinea corn were grown. In addition, livestock manures are routinely used to enhance soil nutrients while NIMBUS ${ }^{\circledR}$ Space Spray $(5 \mathrm{~g} / \mathrm{kg}$ soil pyrethrum $+40 \mathrm{~g} / \mathrm{kg}$ soil piperonyl butoxide) is used on the farm to arrest grain weevil infestation.

\section{Source of heavy metal}

Cadmium chloride $\left(\mathrm{CdCl}_{2}\right)$, the source of cadmium used in this study was purchased from Sigma Aldrich Corp (St Louis MO, USA).

\section{Sampling, microcosm setup, physicochemical and heavy metal content analysis}

Soil samples were collected from upper 10-12 cm using a sterile hand trowel after removing the debris from the soil surface. The soil samples, collected via composite sampling were passed through a $2-\mathrm{mm}$ mesh sieve. Sieved soils were made homogenous by thorough mixing in a large plastic bag. Sieved soil (1 kg) weighed and placed in an open pan was designated SL4. The second soil microcosm designated SL5 contained $1 \mathrm{~kg}$ of sieved 
soil amended with $250 \mathrm{mg} \mathrm{CdCl}$, respectively. The two setups (in triplicates) were incubated at room temperature for 5 weeks and flooded weekly with $50 \mathrm{ml}$ distilled water to maintain a moisture content of $25 \%$.

The $\mathrm{pH}$ of the soil samples was measured using a $\mathrm{pH}$ meter (model 3051, Jenway, UK) by dipping the glass electrode in a soil solution slurry that contains a fivefold volume of water containing $1 \mathrm{M} \mathrm{KCl}$. Moisture and total organic matter contents were determined gravimetrically, while total nitrogen content was determined by macroKjeldahl digestion method. Potassium content was determined by flame photometry (Flame photometer model PFP-7, Buck Scientific Inc, USA) method while phosphorus content was determined spectrophotometrically. Heavy metals composition of the soils was determined using atomic absorption spectrophotometer (model Alpha 4, Chem Tech Analytical, UK) following mixed acid digestion and extraction of the soil samples.

\section{Total DNA extraction and shotgun metagenomics}

Total DNA used for metagenomic analysis was extracted directly from the two soil microcosms, SL4 and SL5. To unravel the microbial community structure of the agricultural soil prior to $\mathrm{Cd}$ amendment, total DNA was extracted from the agricultural soil (SL4) immediately after sampling. For metagenomic evaluation of the effects of cadmium contamination $\left(250 \mathrm{mg} \mathrm{kg}^{-1}\right)$ on the microbial community of the agricultural soil, the total DNA was extracted from SL5 microcosm 5 weeks post-Cd amendment. Total DNA were extracted from the sieved soil samples $(0.25 \mathrm{~g})$ using ZYMO soil DNA extraction Kit (Model D 6001, Zymo Research, USA) following manufacturer's instructions. The quality and concentration of the extracted total DNA was ascertained using NanoDrop spectrophotometer and electrophoresed on a $0.9 \%$ $(\mathrm{w} / \mathrm{v})$ agarose gel, respectively. Shotgun metagenomics of SL4 and SL5 microcosms was prepared using the Illumina Nextera XT sample processing kit and sequenced on a MiSeq. The protocols for total DNA preparation for Illumina shotgun sequencing were as described previously (Salam 2018; Salam and Ishaq 2019).

\section{Processing of fastq raw reads, quality control, assembly and taxonomic classification}

Processing and quality control of fastq raw reads, assembly and taxonomic classification were carried out using the analysis tools in EDGE Bioinformatics web server ( $\mathrm{Li}$ et al. 2017). The pre-processing of the raw Illumina fastq file of the two metagenomes (SL4 and SL5) for quality control check, de novo assembly of the trimmed reads and assembly validation were carried out using FastQ Quality Control Software (FaQCs) (Lo and Chain 2014),
IDBA-UD (Peng et al. 2012), and Bowtie2 (Langmead and Salzberg 2012), respectively.

Read-based and contig-based classifications in the EDGE Bioinformatics web-server were deployed for taxonomic classification of the SL4 and SL5 metagenomes. Although there are several read-based classification tools (GOTTCHA, Kraken, MetaPhlAN, BWA) in the EDGE, Kraken (Wood and Salzberg 2014) was selected for readbased taxonomic classification of the metagenomes due to the depth and accurateness of its database. Contigbased taxonomic classification is premised on alignment of the SL4 and SL5 contigs to NCBI's RefSeq database using the BWA-mem aligner. Metagenomic data of SL4 and SL5 have been deposited and made public in EDGE Bioinformatics web server.

\section{Functional annotation of metagenomics reads}

Sequence reads generated from each of the metagenome were assembled individually using the make.contig command in the MOTHUR metagenomic analysis suite (Schloss et al. 2009). Gene calling was performed on the SL4 and SL5 sequence reads using MetaGene (Noguchi et al. 2006) to predict open reading frames (ORFs). The predicted genes were functionally annotated using the KEGG KofamOALA (Aramaki et al. 2019), which assigns $\mathrm{K}$ numbers to the predicted genes by HMMER/ HMMSEARCH against KOfam (a customized HMM database of KEGG Orthologs). Other functional annotation tools used include the NCBI's conserved domain database CDSEARCH/cdd v 3.15 (CDD; MarchlerBauer et al. 2015), PANNZER2 (Protein Annotation with Z-score) designed to predict the functional description (DE) and GO (Gene Ontology) classes (Törönen et al. 2018), and BacMet (Pal et al. 2014), a function-specific bioinformatics resource for detection of antibacterial biocide and metal-resistance genes.

In BacMet, the predicted genes (protein sequences of SL3 and SL4) were presented as query to the BacMet database (version 2.0) of predicted resistance genes (using default parameters) for identification of metalresistance genes in the query sequences. A modified stand-alone version of the BLAST program (NCBI, version 2.2.2) implemented in the BacMet web server was used for similarity searches against the BacMet sequence databases.

\section{Statistical analysis}

The effects of Cd contamination on the soil physicochemistry and the microbial community structure was statistically analysed using the $t$ test tool in the Analysis ToolPak of Microsoft Excel 2013 software. 


\section{Results}

\section{Physicochemical properties and heavy metals content}

The physicochemical properties and heavy metal content of the agricultural soil (SL4) and cadmium-contaminated agricultural soil (SL5) are shown in Table 1. The $\mathrm{pH}$ of the soil, which is close to neutral $(6.87 \pm 0.28)$ in SL4 became weakly acidic in SL5 $(6.60 \pm 0.06)$. The moisture content, which is less than $7 \%(6.75 \pm 0.01)$ in SL4 dropped further to $4 \%$ in SL5 $(4.32 \pm 0.01)$. All the other physicochemical parameters also showed a declining trend in SL4 (Table 1). Statistical analysis of the physicochemical parameters of the two metagenomes revealed that the difference is statistically significant $(P<0.05$; $P=0.036)$. In addition, significant traces of heavy metals were detected in the soil. While the concentrations of lead $(0.02 \pm 0.002 \mathrm{mg} / \mathrm{kg})$, selenium $(0.006 \pm 0.001 \mathrm{mg} /$ $\mathrm{kg})$, and $\mathrm{Cd}(0.15 \pm 0.001 \mathrm{mg} / \mathrm{kg})$ detected in the agricultural soil are considerably low, high concentrations of zinc, iron, copper, and chromium were detected in the agricultural soil SL4. However, apart from Cd, the concentrations of the heavy metals substantially decrease in SL5 (Table 1).

\section{General characteristics of the metagenomes}

Illumina shotgun next-generation sequencing of the total DNA from the two soil microcosms revealed 73,402 and 46,294 sequence reads for SL4 and SL5, respectively. The SL4 and SL5 metagenomes consisted of 21,042,303 and $12,428,339 \mathrm{bp}$, mean sequence length of $286.67 \pm 59.44$ and $268.47 \pm 86.22 \mathrm{bp}$, and mean GC contents of

Table 1 Physicochemistry and heavy metals content of agricultural soil (SL4) and cadmium-contaminated agricultural soil (SL5)

\begin{tabular}{lcl}
\hline & \multicolumn{1}{l}{ SL4 } & SL5 \\
\hline $\begin{array}{l}\text { Physicochemical parameters } \\
\text { pH }\end{array}$ & $6.87 \pm 0.28$ & $6.60 \pm 0.06$ \\
Moisture (\%) & $6.75 \pm 0.01$ & $4.32 \pm 0.01$ \\
Total organic matter (\%) & $73.21 \pm 0.21$ & $64.79 \pm 1.90$ \\
Total nitrogen (\%) & $53.48 \pm 0.69$ & $36.08 \pm 2.13$ \\
Phosphorus (mg/kg) & $29.41 \pm 0.82$ & $22.15 \pm 1.39$ \\
Potassium (mg/kg) & $17.880 \pm 0.002$ & $12.160 \pm 0.003$ \\
Heavy metals content & & \\
Lead (mg/kg) & $0.020 \pm 0.001$ & $\mathrm{ND}$ \\
Chromium (mg/kg) & $5.910 \pm 0.003$ & $3.580 \pm 0.002$ \\
Cadmium (mg/kg) & $0.150 \pm 0.001$ & $62.800 \pm 0.002$ \\
Zinc (mg/kg) & $14.080 \pm 0.003$ & $7.760 \pm 0.004$ \\
Iron (mg/kg) & $13.940 \pm 0.003$ & $7.230 \pm 0.005$ \\
Copper (mg/kg) & $12.580 \pm 0.001$ & $8.220 \pm 0.004$ \\
Selenium (mg/kg) & $0.006 \pm 0.001$ & $\mathrm{ND}$ \\
\hline
\end{tabular}

ND not detected
$55.08 \% \pm 12.49$ and $54.20 \% \pm 10.61$, respectively. After trimming, dereplication, and quality control, sequence reads in SL4 and SL5 reduced to 69,514 (94.70\%) and 40,658 (87.83\%) with 20,902,030 (99.33\%) and 12,216,171 (98.29\%) bp, mean sequence lengths of $300.69 \pm 4.38$ and $300.46 \pm 7.23 \mathrm{bp}$, and mean GC contents of $57.49 \% \pm 4.94$ and $55.70 \% \pm 4.49$, respectively. Other general features of the soil metagenomes are indicated in Table 2.

\section{Taxonomic characterization of the metagenomes}

Taxonomic characterization of the agricultural soil (SL4) revealed 29 phyla with the preponderance of the phyla Proteobacteria (37.38\%), Actinobacteria (35.26\%), Bacteroidetes (13.45\%), and Firmicutes (9.47\%). In cadmiumcontaminated SL5 microcosm, 25 phyla were recovered with the predominance of Proteobacteria (50.50\%), Actinobacteria (17.17\%), Firmicutes (16.42\%), and Bacteroidetes (10.70\%). In SL5, 68.05\% of members of Actinobacteria were lost while there is massive reduction in the population of members of the phyla Candidatus Saccharibacteria, Chloroflexi, and Nitrospirae. In contrast, there is a massive upsurge in the population of members of the phyla Euryarchaeota (an archaeal phylum), Chlamydiae, Spirochaetes, and Deferribacteres in SL5 microcosm (Fig. 1).

In class delineation, 42 and 38 classes were retrieved from SL4 and SL5 metagenomes with the dominance of Actinobacteria (35.02\%), Alphaproteobacteria (12.31\%), Betaproteobacteria (10.93\%), and Gammaproteobacteria (8.99\%) in SL4 and Alphaproteobacteria (22.28\%), Actinobacteria (18.36\%), Gammaproteobacteria (15.54\%), and Bacilli (11.34\%) in SL5. In SL5, Massive decline was observed in the population of members of the classes Actinobacteria, Rubrobacteridae, Negativicutes, Acidimicrobidae and Nitrospira while there is a huge upscale in the population of members of the classes Methanomicrobia, Chlamydiia and Spirochaetia (Fig. 2).

In order classification where 94 and 78 orders were recovered in SL4 and SL5 metagenomes, there is preponderance of Actinomycetales (25.81\%), Burkholderiales (8.01\%) and Bacteroidales (7.19\%) in SL4 while Actinomycetales (17.18\%), Rhizobiales (8.51\%) and Burkholderiales (8.35\%) dominates in SL5 (Additional file 1: Figure S1). In family delineation, 158 and 126 families were retrieved from SL4 and SL5 metagenomes. Caulobacteraceae (8.70\%), Alcaligenaceae (7.10\%), and Sphingobacteriaceae (6.12\%) dominates in SL4 while Enterobacteriaceae (7.94\%), Alcaligenaceae (7.45\%) and Methyobacteriaceae (6.61\%) were preponderant in SL5 (Additional file 1: Figure S2).

In genus delineation, 270 and 205 genera were recovered in SL4 and SL5 metagenomes. The genera with the highest representation in SL4 include Prevotella (6.93\%), 
Table 2 General characteristics of SL4 and SL5 metagenomes

\begin{tabular}{|c|c|c|}
\hline & SL4 & SL5 \\
\hline \multicolumn{3}{|l|}{ 1. Pre-processing } \\
\hline \multicolumn{3}{|l|}{ a. Raw reads } \\
\hline Reads & 73,402 & 46,294 \\
\hline Total bases (bp) & $21,042,303$ & $12,428,339$ \\
\hline Mean read length (bp) & $286.67 \pm 59.44$ & $268.47 \pm 86.22$ \\
\hline Mean GC content (\%) & $55.08 \pm 12.49$ & $54.20 \pm 10.61$ \\
\hline \multicolumn{3}{|l|}{ b. Quality trimming } \\
\hline \multicolumn{3}{|l|}{ Trimmed reads } \\
\hline Reads & $69,514(94.70 \%)$ & $40,658(87.83 \%)$ \\
\hline Total bases (bp) & $20,902,030(99.33 \%)$ & $12,216,171(98.29 \%)$ \\
\hline Mean read length (bp) & $300.69 \pm 4.38$ & $300.46 \pm 7.23$ \\
\hline Mean GC content (\%) & $57.49 \pm 4.94$ & $55.70 \pm 4.49$ \\
\hline Paired reads & $69,494(99.97 \%)$ & $40,604(99.87 \%)$ \\
\hline Paired total bases & 20,896,965 (99.98\%) & $12,200,818(99.87 \%)$ \\
\hline Unpaired reads & $20(0.03 \%)$ & $54(0.13 \%)$ \\
\hline Unpaired total bases & $5065(0.02 \%)$ & $15,353(0.13 \%)$ \\
\hline \multicolumn{3}{|l|}{ 2. Assembly and annotation } \\
\hline \multicolumn{3}{|l|}{ a. De novo assembly by idba_ud } \\
\hline Number of contigs & 117 & 76 \\
\hline N50 (bp) & 420 & 424 \\
\hline Max contig size (bp) & 458 & 462 \\
\hline Min contig size (bp) & 255 & 270 \\
\hline Total assembly size (bp) & 47,020 & 30,607 \\
\hline \multicolumn{3}{|c|}{ b. Assembly validation by read mapping } \\
\hline Number of mapped reads & 40,629 & 23,795 \\
\hline$\%$ of total reads & $58.45 \%$ & $58.52 \%$ \\
\hline Number of unmapped reads & 28,885 & 16,863 \\
\hline$\%$ of total reads & $41.55 \%$ & $41.48 \%$ \\
\hline Average fold coverage & $214.34 X$ & $204.18 X$ \\
\hline
\end{tabular}

Conexibacter (5.91\%), Brevundimonas (5.02\%), and Bifidobacterium (4.46\%). In Cd-contaminated SL5 metagenome, the predominant genera include Methylobacterium (9.14\%), Streptococcus (4.29\%), Paenibacillus (3.74\%), and Prevotella (3.67\%). Massive decline was observed in the population of Caulobacter, Acinetobacter, Megasphaera, Conexibacter, Burkholderia, Prevotella and several others in SL5. In contrast, massive enrichment in the population of Methylobacterium, Paenibacillus, Modestobacter, Methanosaeta, Flexistipes, Desulfomicrobium, Arcobacter and few others were observed in the Cd-contaminated SL5 metagenome (Fig. 3). Statistically significant $(P<0.05 ; P=0.0016)$ difference in genus delineations was observed between SL4 and SL5 metagenome.

In species delineation, 310 and 230 species were retrieved from SL4 and SL5 metagenomes. The preponderant species in SL4 metagenome are Conexibacter woesei (8.93\%), Brevundimonas subvibrioides (7.58\%),
Sphingobacterium sp. 21 (6.47\%), and Pedobacter saltans (4.59\%). In Cd-amended SL5 metagenome, the dominant species are Methylobacterium radiotolerans (12.80\%), Sphingobacterium sp. 21 (4.86\%), Modestobacter marinus $(4.60 \%)$ and Sphingomonas wittichii (3.60\%), respectively. Population of C. woesei, Acinetobacter baumannii, Megasphaera elsdenii, Acidimicrobium ferrooxidans and several others massively nosedived in SL5 while species such as $M$. radiotolerans, M. marinus, Methanosaeta concilii, Flexistipes sinusarabici and many others were massively enriched (Fig. 4). Statistically significant $(P<0.05 ; P=0.01)$ difference in species delineations was observed between SL4 and SL5 metagenome.

Contig-based classification of the metagenomes (SL4 and SL5) conducted by aligning the SL4 and SL5 contigs to NCBI's RefSeq database using the BWA-mem aligner is indicated in Additional file 1: Figs. S3 to S8. 


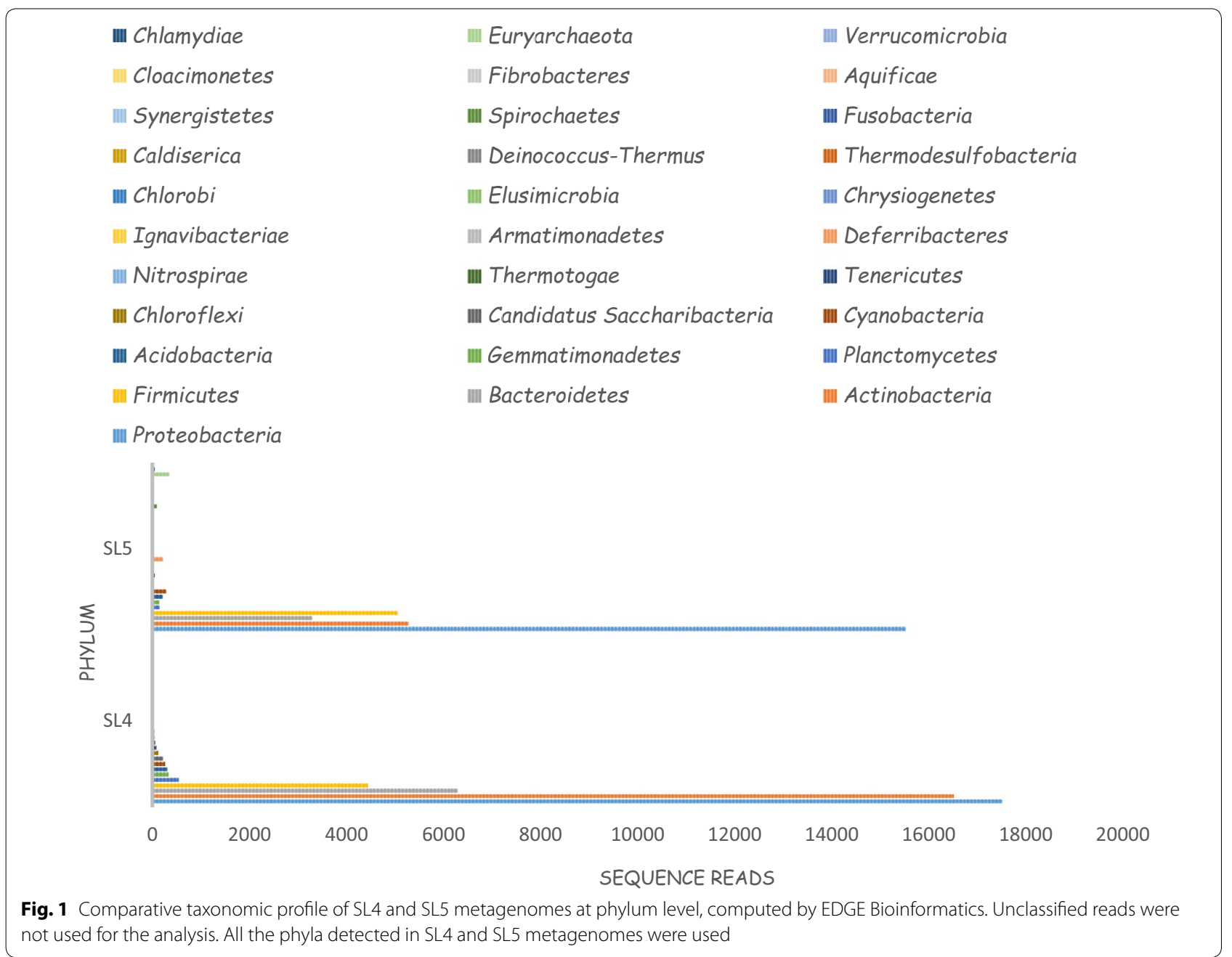

\section{Functional annotation of the metagenomes}

Functional characterization of the metagenomes revealed significant differences. In SL4 metagenome, putative genes for carbohydrate metabolism (fructose-6-phosphate aldolase 2; arabinoxylan arabinofuranohydrolase; 2-dehydro-3-deoxygluconokinase/2-dehydro-3-deoxygalactonokinase), nitrogen metabolism (CFP/FNR family transcriptional regulator, nitrogen oxide reductase regulator), sulphur metabolism (sulphite oxidase), methane metabolism (Ni-sirohydrochlorin a,c-diamide reductive cyclase, play a key role in methanogenesis and anaerobic methane oxidation), and autotrophic $\mathrm{CO}_{2}$ assimilation (energy-converting hydrogenase B) were detected. Other putative genes detected include genes responsible for biosynthesis of bioactive compounds and antibiotics (fumagillin biosynthesis methyltransferase, nocardicin $\mathrm{N}$-oxygenase, trigonelline monooxygenase, oxygenase component), xenobiotic degradation (cyanamide hydratase, cytochrome P450 RapN, poly(3hydroxyoctanoate) depolymerase), and stress response (diacylglycerol diphosphate phosphatase/phosphatidate phosphatase).

In SL5 metagenome, putative genes and enzymes were detected for carbohydrate metabolism (2,3-bisphosphoglycerate-independent phosphoglycerate mutase, UDPglucose-4 epimerase), amino acid metabolism (cysteine desulfurase, tryptophan synthase beta chain), xenobiotic degradation (carboxylesterase 1, alkene monooxygenase, effector subunit), polyketide synthases (nogalonic acid methyl ester cyclase/aklanonic acid methyl ester cyclase), and vitamin $\mathrm{B}_{12}$, porphyrin and chlorophyll metabolism (adenosylcobinamide-phosphate synthase).

Functional annotation of the predicted genes in SL4 and SL5 metagenomes for heavy metals resistance genes using the BacMet database revealed interesting findings. Diverse protein families responsible for transport, uptake and efflux of heavy metals were detected in the two metagenomes (Tables 3, 4). In agricultural soil SL4 metagenome, putative genes for transport, uptake, and efflux of copper $(\operatorname{cop} A, \operatorname{cop} B, \operatorname{cop} C, \operatorname{cop} P$, multicopper 


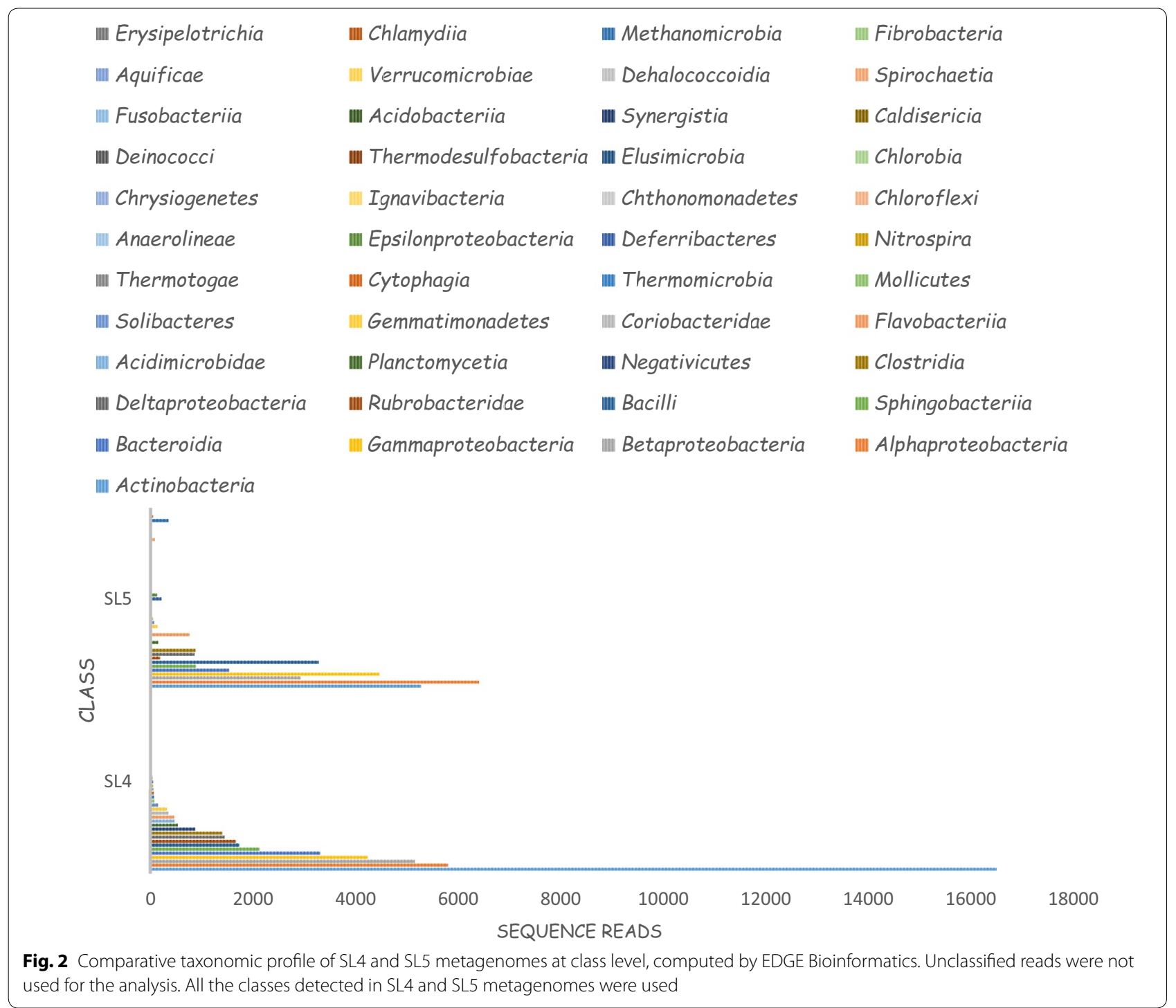

oxidase type 2 and 3; CueO, cutC, cutE, etc.), chromium, cadmium, nickel, cobalt (chrA, $\operatorname{chr} B$, nikA, nikB, $n i k R$, cadmium-translocating P-type ATPase, nickelcadmium-cobalt resistance protein nccC, etc.) were detected. Other putative genes detected include resistance genes for iron, zinc, magnesium, manganese (fur $A$, BasS/PmrB, zinc/iron ZIP family permease, $m g t B$; magnesium-translocating P-type ATPase; NRAMP family $\mathrm{Mn}^{2+} / \mathrm{Fe}^{2+}$ transporter, etc.) and mercury, silver, molybdenum, lead, arsenic, tungsten, tellurium and antimony (merA, merB, merR, merH, merP, pbrA, $\bmod A, \bmod B$, $\bmod C, \operatorname{Trg} B, \operatorname{Teh} A, W t p A$, arsenite oxidase, arsB, arsC, arsM, etc.) (Table 3).

In Cd-contaminated SL5 metagenome, putative genes were detected for cadmium, cobalt, nickel, zinc (heavy metal-translocating P-type ATPase, $c z c A, c z c D, c z r A$, $c z r B, z r a R$, zraP, znuA, cobalt-zinc-cadmium resistance protein, $n i k A, n i k R$, nikD, nikE, etc.), and copper, magnesium, and silver $(\operatorname{cop} A, \operatorname{cop} B, \operatorname{cop} C$, magnesiumtransporting ATPase, $\operatorname{cor} A$, copper/silver efflux P-type ATPase, etc.). Also detected are putative resistance genes for iron, lead, chromium, manganese, tellurium, selenium ( $f p v A 2$ gene, fur, $f b p C$, ferroxidase, ctpC gene, tehB, $\operatorname{chr} A$, $\operatorname{chr} C, \operatorname{trg} B$, etc.), and mercury, arsenic, molybdenum and tungsten (merA, merR, merT, merB1, arsB, ars $C$, ars $H$, arsenite oxidase, $\operatorname{ars} M, \bmod B, w t p A$, etc.) (Table 4).

It was observed that putative genes, responsible for cadmium homeostasis, transport, efflux and detoxification such as $c z c A, c z c D, c z r A, c z r B$, manganese transport protein, and manganese/iron superoxide dismutase (MnSOD, $\operatorname{sod} A$; FeSOD, $\operatorname{sod} B)$ which were detected in Cd-amended SL5 metagenome were conspicuously 


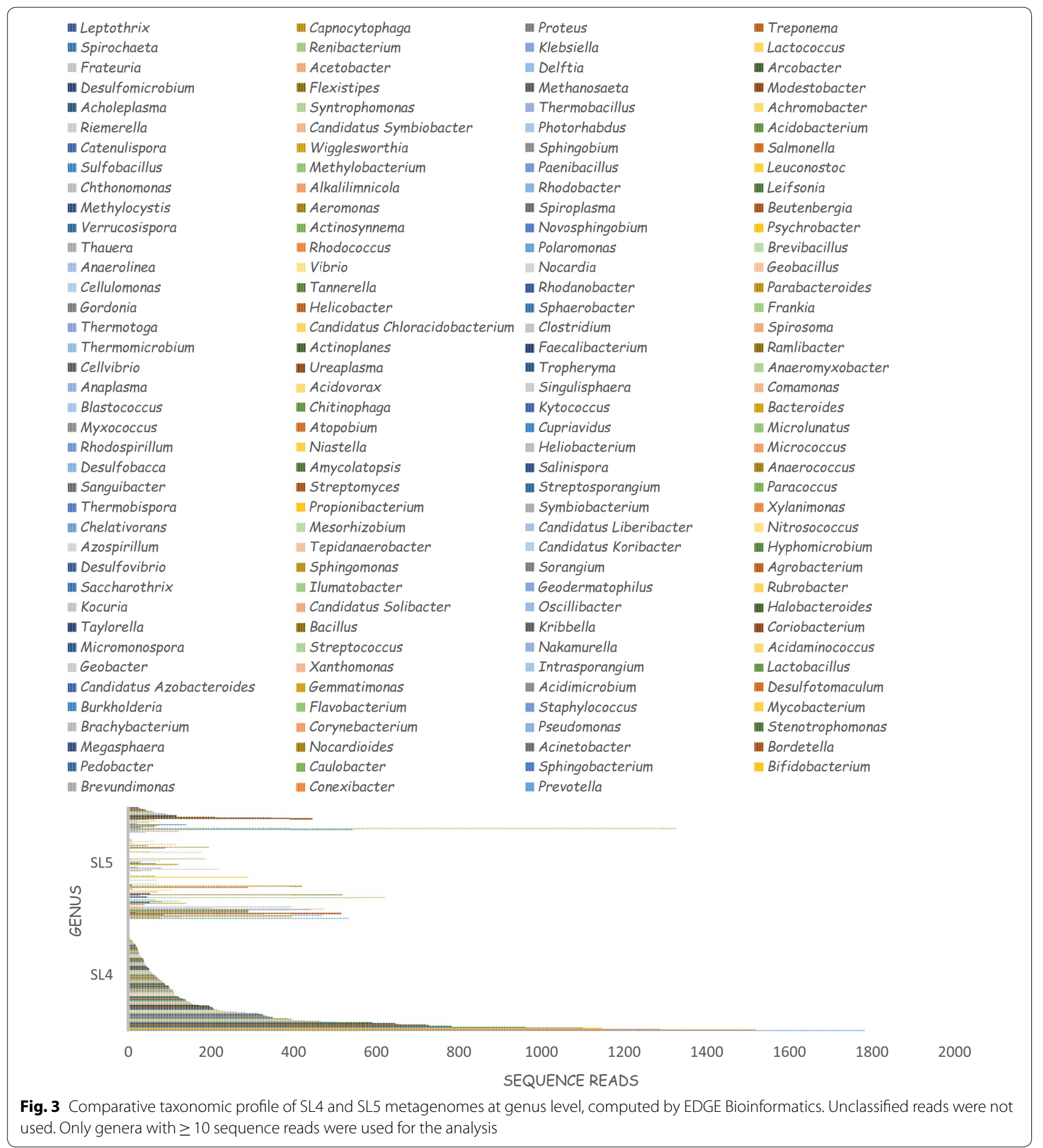

absent in SL4 metagenome. It was also observed based on functional annotation of protein sequences in $\mathrm{Cd}$ amended SL5 metagenome using PANNZER2 that one thousand four hundred and forty (1440) of the sequences were annotated for alkyl hydroperoxide reductase $(\mathrm{AhpC})$, an organic hydroperoxide detoxification enzyme.
However, the AhpC gene was not detected in the protein sequences of SL4 metagenome. 


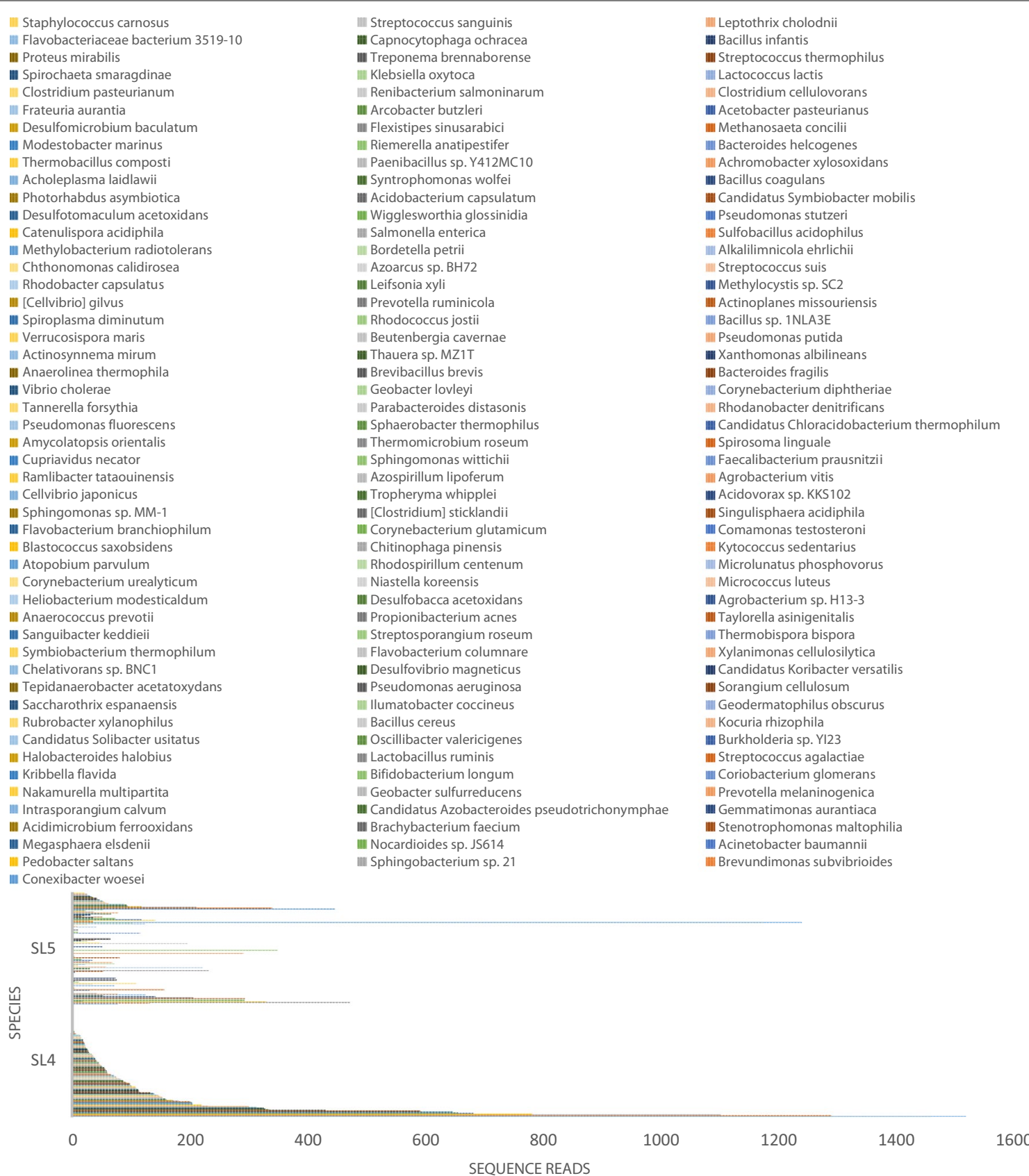

Fig. 4 Comparative taxonomic profile of SL4 and SL5 metagenomes at species level, computed by EDGE Bioinformatics. Unclassified reads were not used. Only species with $\geq 10$ sequence reads were used for the analysis

\section{Discussion}

Point and non-point release of heavy metals and metalloids into soil environments via atmospheric deposition and diverse agricultural activities have negatively impacted soil ecological balance, alter soil physicochemistry and biogeochemistry, reduce soil microbial diversity and pose serious health risk to animals and humans (Feng et al. 2018; Rai et al. 2019; Salam et al. 2019). In this study, all the physicochemical parameters considerably reduce in Cd-amended SL5 microcosm, though not as profound as those reported in our previous study on mercury (Salam et al. 2019). This may be attributed to $\mathrm{Cd}$ contamination. Previous reports have indicated that increase in soil $\mathrm{pH}$ increases Cd sorption to soil organic matter (Gray et al. 1998, 1999). The decrease in soil pH observed in SL5 microcosm may thus be indicative of 


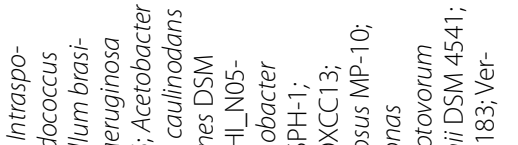

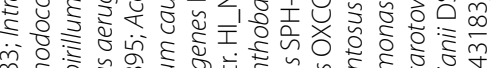

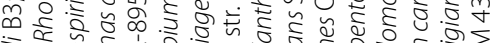

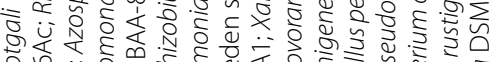

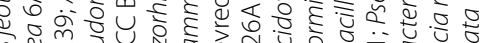

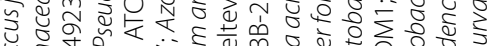

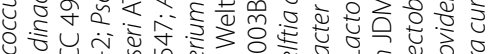

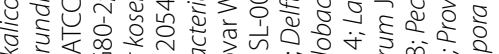

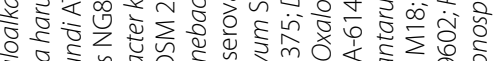

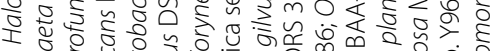

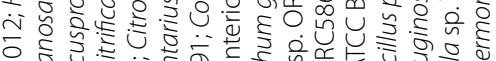

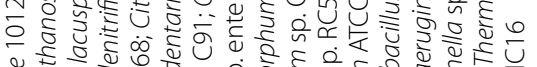

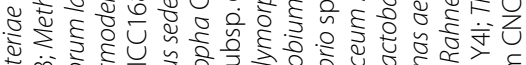

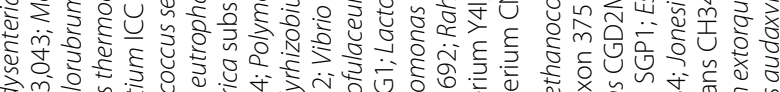

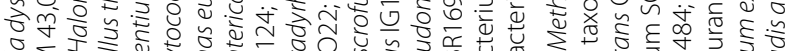

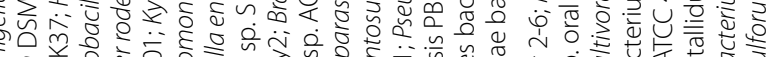

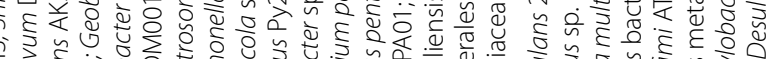

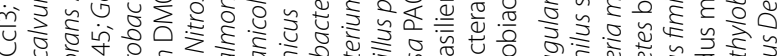

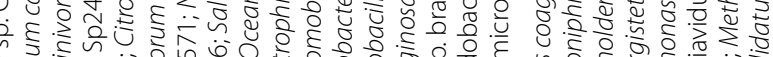

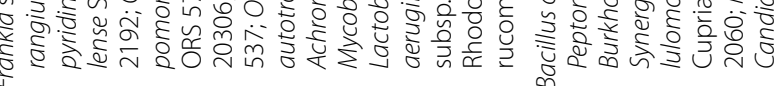

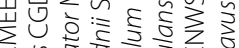

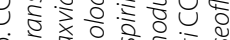

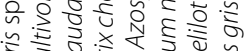

है है

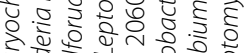

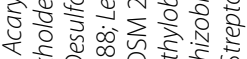

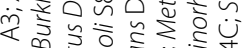

\& 0.00

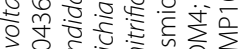

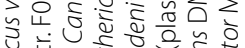

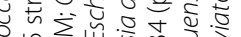

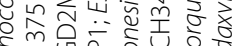

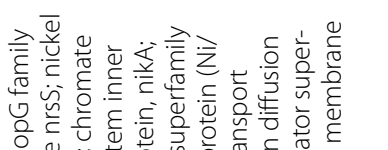

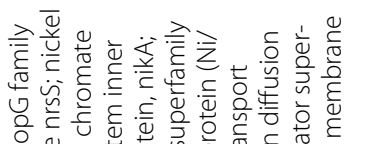

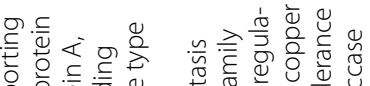

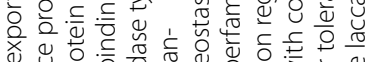

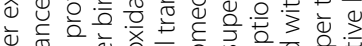

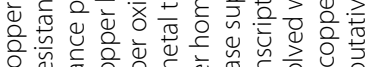

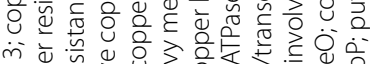

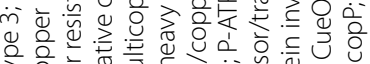

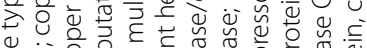

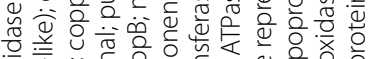

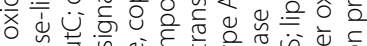

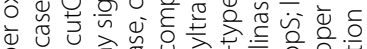

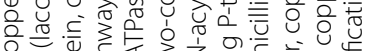

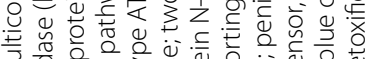

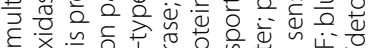

نे

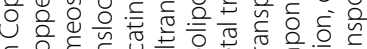

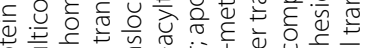

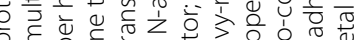

Q

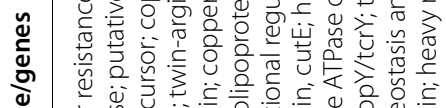

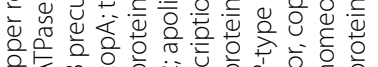

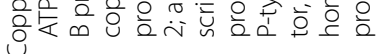

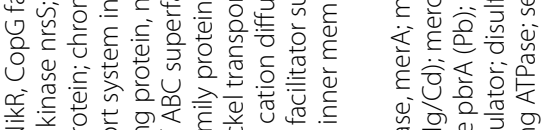

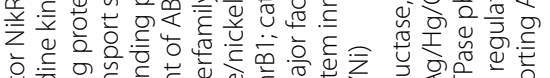

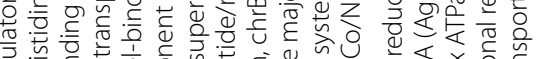

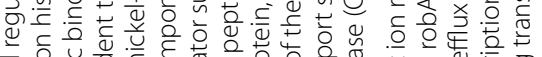

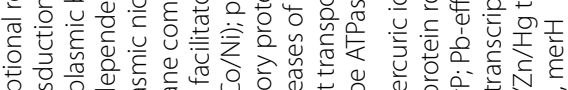

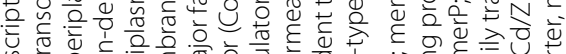

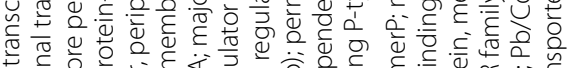

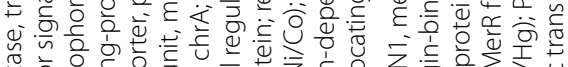

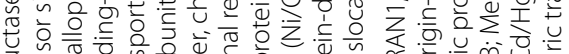

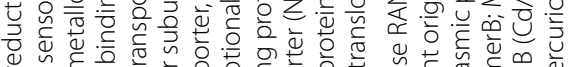

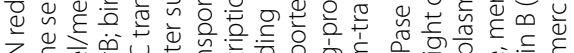

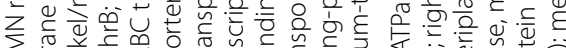

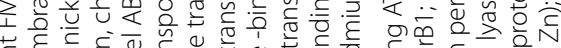

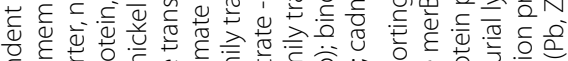

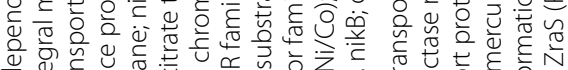

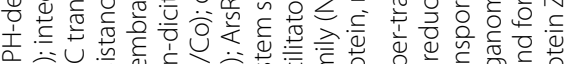

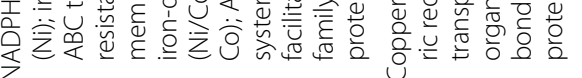

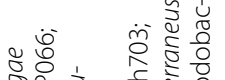

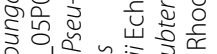

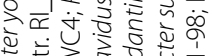

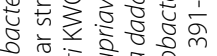

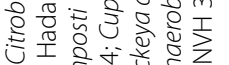

公要

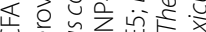

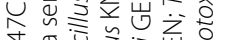

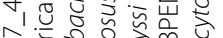

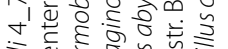

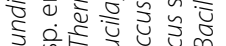

खे हूँ

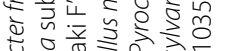

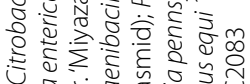

i力

ơ

के है을

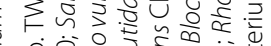

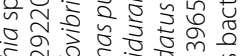

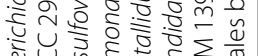

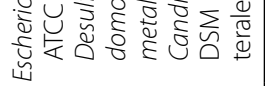

\section{官要 产}

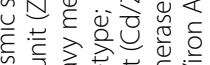

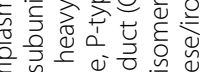

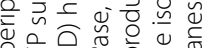

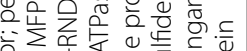

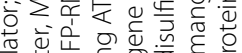

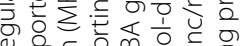

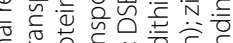

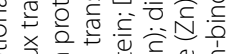

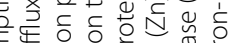

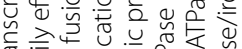

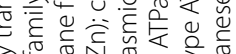

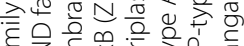

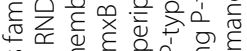

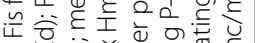

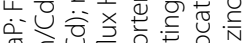

N

这.

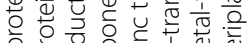

음

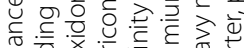

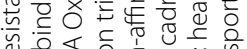

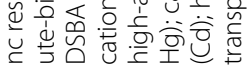

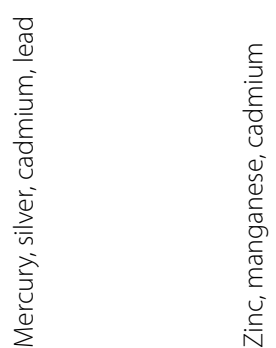

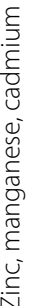




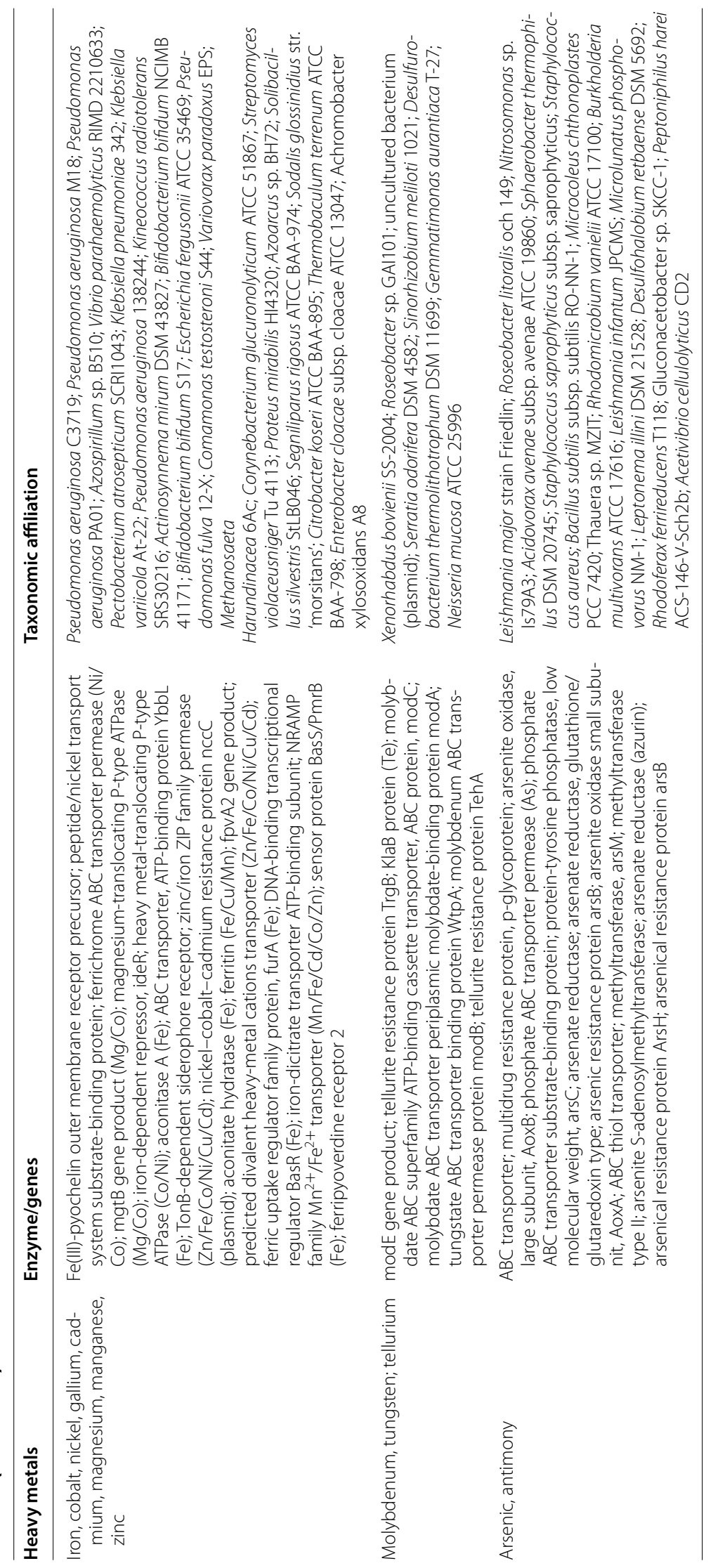




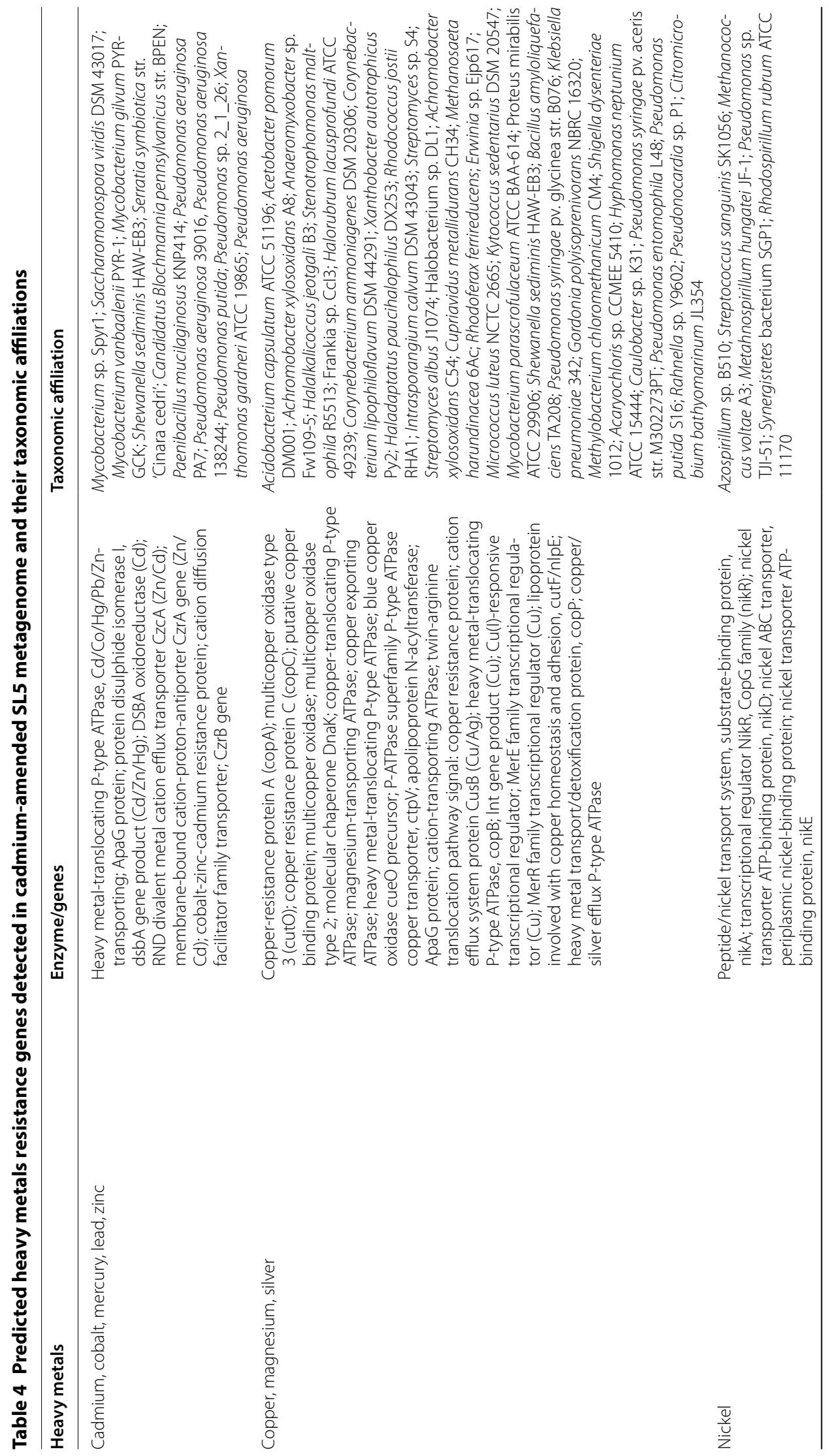


Salam et al. Bioresour. Bioprocess.

(2020) 7:25

Page 13 of 19






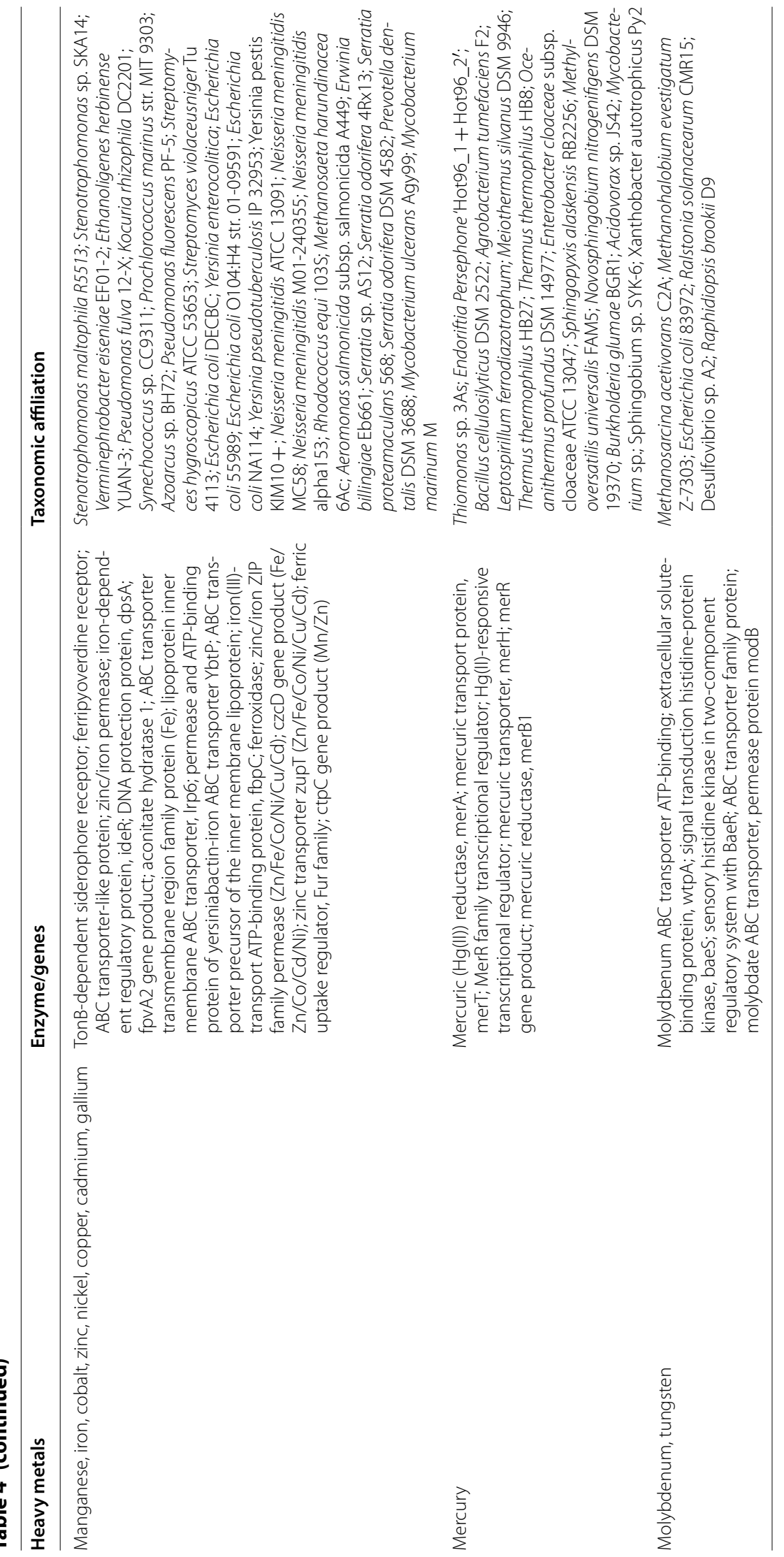


solubility of cadmium in the soil and its availability in soil solution.

The detection of various heavy metals in SL4 agricultural soil as revealed in the heavy metal content analysis, though at thresholds permitted for soils (WHO/FAO 2001) may be attributed to atmospheric deposition and various agricultural practices, which introduce the heavy metals into the soil. The significant reduction of these metals in Cd-amended SL5 microcosm may be due to several reasons. First, utilization of biologically important heavy metals such as zinc, copper, iron and chromium are tightly linked to the metabolic functioning of soil biota as they are essential micronutrients required by most microorganisms, which possibly cause their reduction (Bruins et al. 2000; Marschner 2012; Rai et al. 2019). Also, addition of $\mathrm{Cd}$ to the agricultural soil induces the activation of $\mathrm{Cd}$ resistance systems, which are also used by microorganisms for uptake, transport, efflux, and detoxification of other heavy metals detected in this study (Nies 1999, 2003).

The predominance of the phyla Proteobacteria and Actinobacteria in the agricultural soil is not surprising as the two phyla comprise members that are well adapted to agricultural soils (Cheema et al. 2015; Trivedi et al. 2016; Salam et al. 2017; Yin et al. 2017). The exhibition of filamentous growth, possession of spores that are recalcitrant to various environmental stressors, and secretion of avalanche of enzymes, which degrade various macromolecules that abound in soil provide distinctive edge for members of Actinobacteria phylum in soil environments (Larkin et al. 2005; Salam and Obayori 2019). Members of the phylum Proteobacteria have diverse morphological, physiological, and metabolic properties. These properties facilitate their preponderance in soils with various environmental conditions (Aislabie and Deslippe 2013; Montecchia et al. 2015; Salam et al. 2019).

While about $11 \%$ of proteobacterial members were lost due to Cd contamination in SL5, it still constitutes the most abundant phylum (50.50\%). In contrast, though the second most abundant phylum in SL5 (17.17\%), the phylum Actinobacteria loses $68.05 \%$ of its members. This may be due to $\mathrm{Cd}$ toxicity to majority of its members, which results in oxidative damage via production of reactive oxygen species, and displacement of $\mathrm{Zn}$ and Fe ions from metalloproteins, resulting in their inactivation (Vallee and Ulmer 1972; Stohs and Bagchi 1995; Fortuniak et al. 1996; Stohs et al. 2001; Banjerdkij et al. 2005).

Structural analysis of the SL5 metagenome revealed the dominance of the class Alphaproteobacteria and the genus Methylobacterium. The preponderance of members of the class and the genus may be attributed to several factors. The preponderance of czrCBA efflux system and other $\mathrm{Cd}$ uptake/transport/efflux systems among members of the class Alphaproteobacteria may have contributed immensely to their abundance in SL5 system. The czrCBA efflux system is involved mainly in response to $\mathrm{Cd}$ and zinc showing significant induction in their presence (Nies 2003; Braz and Marques 2005; $\mathrm{Hu}$ et al. 2005; Valencia et al. 2013). In addition, members of the genus Methylobacterium are reputed to be widely distributed in diverse environmental compartments with propensity for detoxification of heavy metals (De Marco et al. 2004; Fernandes et al. 2009; Salam et al. 2015). They are renowned for possession of heavy metal resistance genes such as cation efflux system protein czcA gene, ABC transporters involved in metal uptake, copper-translocating P-type and genes encoding arsenic resistance and chromate transport (Madhaiyan et al. 2007; Dourado et al. 2012; Kwak et al. 2014; Dourado et al. 2015).

Functional characterization of the two metagenomes (SL4, SL5) revealed the presence of heavy metal resistance genes (Tables 3,4). Detection of resistance genes in SL4 agricultural soil metagenome is not surprising as traces of various heavy metals were detected in the soil (Table 1). The survival of some members of the community despite the heavy metals stress indicates the presence of resistance systems that tightly control intracellular concentrations of the heavy metal ions and their attendant toxicities (Nies 1999, 2003; Hu et al. 2005).

One of the toxic effects of $\mathrm{Cd}$ is that it causes oxidative stress by depleting glutathione and protein-bound sulfhydryl groups resulting in formation of reactive oxygen species (ROS). The resultant ROS causes enhanced lipid peroxidation, DNA damage and distorted calcium and sulfhydryl homeostasis (Kachur et al. 1998). In this study, thioredoxin-based thiol disulfide oxidoreductase $(d s b A$, $d s b B$ ) and dithiol disulfide isomerase, which protect microbial cells against oxidative stress were detected in the two metagenomes. However, manganese/iron superoxide dismutase, two superoxide dismutases known to remove superoxide radicals that may be generated upon exposure to heavy metals (Jones et al. 1991; Stohs and Bagchi 1995; Kachur et al. 1998; Nies 1999) were only detected in SL5 metagenome. This is interesting as previous reports have averred that the greatest induction of Mn superoxide dismutase $(\operatorname{sod} A)$ occurred under $\mathrm{Cd}$ and chromium stress, while induction of Fe superoxide dismutase $(\operatorname{sodB})$ occurred only under $\mathrm{Cd}$ stress ( Hu et al. 2005; Ammendola et al. 2014). Thus, the induction of these two intracellular superoxide dismutases required to control Cd-mediated oxidative stress in SL5 metagenome could only be attributed to elevated concentration of $\mathrm{Cd}$ in SL5 microcosm.

Another interesting finding is the detection of alkyl hydroperoxide reductase $(a h p C)$ gene in 1440 protein 
sequences of SL5 metagenome, which is not detected in the protein sequences of SL4 metagenome. The detection of this gene in SL5 metagenome may be attributed to $\mathrm{Cd}$ contamination. Previous works have reported cadmium-induced cross-protection against $\mathrm{H}_{2} \mathrm{O}_{2}$ in E. coli cells pre-treated with $\mathrm{CdCl}_{2}$ while others have reported increase in induction of $\mathrm{AhpC}$ gene by tenfold after cells were exposed to Cd (Ferianc et al. 1998; Mongkolsuk and Helmann 2002; Banjerdkij et al. 2005).

The three major families of efflux transporters involved in $\mathrm{Cd}^{2+} / \mathrm{Zn}^{2+}$ resistance namely the P-type ATPases (Nucifora et al. 1989; Rensing et al. 1997), the CBA transporters (Nies and Silver 1989; Nies 1995; Hassan et al. 1999), and the cation diffusion facilitator (CDF) transporters (Xiong and Jayaswal 1998; Anton et al. 1999; Grass et al. 2001; Nies 2003) were detected in this study. Several P-type ATPases were detected in SL4 (cadmiumtranslocating P-type ATPase; $\mathrm{Pb} / \mathrm{Cd} / \mathrm{Zn} / \mathrm{Hg}$ transporting ATPase; cation transporting P-type ATPase) and SL5 (cadmium-translocating P-type ATPase; heavy metaltranslocating P-type ATPase $\mathrm{Cd} / \mathrm{Co} / \mathrm{Hg} / \mathrm{Pb} / \mathrm{Zn}$-transporting) metagenomes. The functional features of these pumps include maintenance of homeostasis of essential metals $\left(\mathrm{Cu}^{+}, \mathrm{Co}^{2+}, \mathrm{Zn}^{2+}\right)$ and mediating resistance to toxic metals $\left(\mathrm{Cd}^{2+}, \mathrm{Pb}^{2+}, \mathrm{Ag}^{+}\right)$(Rensing et al. 1997, 1999; Lee et al. 2001; $\mathrm{Hu}$ and Zhao 2007; Scherer and Nies 2009).

It is instructive to note that while CBA transporters $(c z c A, c z r A, c z r B)$ were detected in $C d$-amended SL5 metagenome (Table 4), only the nccC (nickel-cadmium-cobalt) protein, which confers resistance to nickel, cadmium and cobalt was detected in the SL4 metagenome (Table 3). The RND protein CzcA component of the three-component CzcCBA (cadmium-zinc-cobalt) efflux system detected in SL5 metagenome mediates the active part of the transport process, determines the substrate specificity and is involved in the assembly of the trans-envelope protein complex. Its presence in a heavy metal-polluted system is exceptional and indicates highlevel resistance to heavy metal ions (Nies et al. 1989; Franke et al. 2003; Nies 2003). Another RND efflux system detected in SL5 metagenome is the czrCBA efflux system, a prototype of the czcCBA efflux system (Hassan et al. 1999; Valencia et al. 2013). It is an efflux system that showed significant induction in the presence of cadmium and zinc. The detection of $c z r A$ and $c z r B$ in SL5 metagenome could only be attributed to $\mathrm{Cd}$ amendment, which upregulate the $c z r$ regulon in the metagenome. CBA transporters mainly carried out outer membrane efflux by removing periplasmic metal ions transported there by ATPases or CDF transporters or expelling the ions before they entered the cytoplasm (Scherer and Nies 2009).
The cation diffusion facilitator (CDF) transporters are represented in $\mathrm{Cd}$-amended SL5 metagenome with the $c z c D$ gene, the archetype of the family. The gene, first described as a regulator of expression of the CzcCBA high-resistance system in Ralstonia (now Cupriavidus) metallidurans strain $\mathrm{CH} 34$ can also mediate resistance to small degree of $\mathrm{Zn}^{2+} / \mathrm{Co}^{2+} / \mathrm{Cd}^{2+}$ in the absence of CzcCBA system (Nies 1992; Anton et al. 1999; Nies 2003).

The interplay of different transporters in $\mathrm{Cd}$ and zinc resistance clearly indicated, as shown in several studies that full resistance to $\mathrm{Cd}^{2+}$ requires both the activity of CBA transporter and P-type ATPase (Legatzki et al. 2003; Scherer and Nies 2009). This is because some $\mathrm{Cd}^{2+}$ can escape the CBA transporter and enter the cytoplasm. In such instance, they will be exported by the P-type ATPases (Scherer and Nies 2009). This perhaps explains the reason why both P-type ATPases and CBA transporters were upregulated in Cd-perturbed SL5 metagenome.

A cursory look at the taxonomic affiliation of the heavy metal genes detected in SL4 and SL5 metagenome revealed they belong exclusively to the two dominant phyla, Proteobacteria and Actinobacteria, with Proteobacteria members largely dominating. This is in tandem with the structural analysis results, which shows the dominance of Proteobacteria and Actinobacteria in the two metagenomes. This is interesting as it revealed that the two phyla not only dominate the 'who is there?' part of the two microbial community, but were equally responsible for the detoxification of Cd (SL5) and other heavy metals in the communities.

\section{Conclusions}

In summary, Illumina shotgun metagenomics and analysis of soil physicochemistry and heavy metals content has revealed the presence of several heavy metals and the effects of $\mathrm{Cd}$ contamination on soil physicochemistry and microbial community structure of SL4 agricultural soil. Detection of various heavy metals in the agricultural soil, though at low threshold is concerning as heavy metals are not biodegradable and can bioaccumulate in the food chain over time. Possession of diverse resistance genes by members of the microbial community may be exploited for depuration of agricultural soils inundated with $\mathrm{Cd}$ and other heavy metals. The need to embrace environmentally friendly methods for pest and herbage control and to improve crop yield is becoming more profound, due to the negative impacts of current agricultural practices on the general wellbeing of the soil ecosystem and its inhabitants. 


\section{Supplementary information}

Supplementary information accompanies this paper at https://doi. org/10.1186/s40643-020-00314-w.

Additional file 1. Additional figures.

\section{Abbreviations}

Cd: Cadmium; CDF: Cation diffusion facilitator; RND: Resistance nodulation division; CBA: Capsule biogenesis/assembly; NRAMP: Natural resistance-associated macrophage protein

\section{Acknowledgements}

Not applicable.

\section{Authors' contributions}

LBS conceived the study and performed the experiments. OSO coordinated the study and in consultation with LBS wrote the Materials and Methods and Results. MOI and OOA contributed to the Discussion section. All authors read and approved the final manuscript.

\section{Funding}

No external funding was received to conduct this study.

\section{Availability of data and materials}

All data generated or analysed during this study are included in this published article and its additional files

\section{Ethics approval and consent to participate}

Not applicable.

\section{Consent for publication}

Not applicable.

\section{Competing interest}

The authors declare that they have no competing interest.

\section{Author details}

${ }^{1}$ Department of Biological Sciences, Microbiology Unit, Summit University, Offa, Kwara, Nigeria. ${ }^{2}$ Department of Microbiology, Lagos State University, Ojo, Lagos, Nigeria. ${ }^{3}$ Department of Microbiology, University of Lagos, Akoka, Lagos, Nigeria

Received: 3 March 2020 Accepted: 5 May 2020

Published online: 11 May 2020

\section{References}

Adriano DC (2001) Trace elements in terrestrial environments: biogeochemistry, bioavailability, and risks of metals, 2nd edn. Springer, New York, p 867

Aislabie J, Deslippe JR (2013) Soil microbes and their contribution to soil services. In: Dymond JR (ed) Ecosystem services in New Zealand-conditions and trends. Manaaki Whenua Press, Lincoln, pp 143-161

Alloway BJ, Steinnes E (1999) Anthropogenic additions of cadmium to soils. In: McLaughlin MJ, Singh BR (eds) Cadmium in soils and plants Developments in plants and soil sciences. Springer, Dordrecht, pp 97-123

Altimira F, Yáñez C, Bravo G, González M, Rojas LA, Seeger M (2012) Characterization of copper-resistant bacteria and bacterial communities from copper-polluted agricultural soils of central Chile. BMC Microbiol 12(1):193

Ammendola S, Cerasi M, Battistoni A (2014) Deregulation of transition metals homeostasis is a key feature of cadmium toxicity in Salmonella. Biometals 27:703-714

Anton A, Grosse C, Reissmann C, Pribyl T, Nies DH (1999) CzCD is a heavy metal ion transporter involved in regulation of heavy metal resistance in Ralstonia sp. strain CH34. J Bacteriol 181:6876-6881
Aramaki T, Blanc-Mathieu R, Endo H, Ohkubo K, Kanehisa M, Goto S, Ogata H (2019) KofamKOALA: KEGG ortholog assignment based on profile HMM and adaptive score threshold. Bioinformatics Btz859

Banjerdkij P, Vattanaviboon P, Mongkolsuk S (2005) Exposure to cadmium elevates expression of genes in the OxyR and OhrR regulons and induces cross-resistance to peroxide killing treatment in Xanthomonas campestris. Appl Environ Microbiol 71(4):1843-1849

Benavides MP, Gallego SM, Tomaro ML (2005) Cadmium toxicity in plants. Braz J Plant Physiol 17(1):21-34

Bhadra B, Nanda AK, Chakraborty R (2005) Inducible nickel resistance in a river isolate of india phylogenetically ascertained as a novel strain of Acinetobacter junii. World J Microbiol Biotechnol 22(3):225-232

Braz VS, Marques MV (2005) Genes involved in cadmium resistance in Caulobacter crescentus. FEMS Microbiol Lett 251:289-295

Bruins MR, Kapil S, Oehme FW (2000) Microbial resistance to metals in the environment. Ecotoxicol Environ Saf 45:198-207

Cheema S, Lavania M, Lal B (2015) Impact of petroleum hydrocarbon contamination on the indigenous microbial community. Ann Microbiol 66:359-369

De Marco P, Pacheco CC, Figueiredo AR, Moradas-Ferreira P (2004) Novel pollutant-resistant methylotrophic bacteria for use in bioremediation. FEMS Microbiol Lett 234:75-80

Dourado MN, Andreote FD, Dini-Andreote F, Conti R, Araujo JM, Araujo WL (2012) Analysis of the 165 rRNA and mxaF genes revealing insights into Methylobacterium niche-specific plant association. Gen Mol Biol 35(1):142-148

Dourado MN, Neves AAC, Santos DS, Araujo WL (2015) Biotechnological and agronomic potential of endophytic pink-pigmented methylotrophic Methylobacterium spp. Biomed Res Int 2015:909016

Edwards JR, Prozialeck WC (2009) Cadmium, diabetes and chronic kidney disease. Toxicol Appl Pharmacol 238(3):289-293

Fashola MO, Ngole-Jeme VM, Babalola OO (2016) Heavy metal pollution from gold mines: environmental effects and bacterial strategies for resistance. Int J Environ Res Public Health 13:1047

Feng G, Xie T, Wang X, Bai J et al (2018) Metagenomic analysis of microbial community and function involved in cd-contaminated soil. BMC Microbiol 18:1

Ferianc P, Farewell A, Nystrom T (1998) The cadmium-stress stimulon of Escherichia coli K-12. Microbiology 144:1045-1050

Fernandes VC, Albergaria JT, Oliva-Teles T, Delerue-Matos C, de Marco P (2009) Dual augmentation foe aerobic bioremediation of MTBE and TCE pollution in heavy metal-contaminated soil. Biodegradation 20(3):375-382

Fortuniak A, Zadzinski R, Bilinski T, Bartosz G (1996) Glutathione depletion in the yeast Saccharomyces cerevisiae. Biochem Mol Biol Int 38:901-910

Franke S, Grass G, Rensing C, Nies DH (2003) Molecular analysis of the copper-transporting efflux system CusCFBA of Escherichia coli. J Bacteriol 185:3804-3812

Grass G, Fan B, Rosen BP, Franke S, Nies DH, Rensing C (2001) ZitB (YbgR), a member of the cation diffusion facilitator family, is an additional zinc transporter in Escherichia coli. J Bacteriol 183:4664-4667

Gray CW, McLaren RG, Roberts AHC, Condron LM (1998) Sorption and desorption of cadmium from some New Zealand soils: effect of $\mathrm{pH}$ and contact time. Australian J Soil Res 36:199-216

Gray CW, McLaren RG, Roberts AHC, Condron LM (1999) Effect of soil pH on cadmium phytoavailability in some New Zealand soils. N Z J Crop Hortic Sci 27:169-179

Handelsman J (2004) Metagenomics: application of genomics to uncultured microorganisms. Microbiol Mol Biol Rev 68:669-678

Hassan MT, van der Lelie D, Springael D, Romling U, Ahmed N, Mergeay M (1999) Identification of a gene cluster, $c z r$, involved in cadmium and zinc resistance in Pseudomonas aeruginosa. Gene 238:417-425

Hu N, Zhao B (2007) Key genes involved in heavy-metal resistance in Pseudomonas putida CD2. FEMS Microbiol Lett 267:17-22

Hu P, Brodie EL, Suzuki Y, McAdams HH, Andersen GL (2005) Whole-genome transcriptional analysis of heavy metal stresses in Caulobacter crescentus. J Bacteriol 187:8437-8449

Imai I, Siegel SM (1973) A specific response to toxic cadmium levels in red kidney bean embryos. Physiol Plant 29:118-120

Jones P, Kortenkamp A, O'Brien P, Wang G, Yang G (1991) Evidence for the generation of hydroxyl radicals from a chromium $(V)$ intermediate isolated 
from the reaction of chromate with glutathione. Arch Biochem Biophys 286:652-655

Júnior CAL, Mazzafera P, Arruda MAZ (2014) A comparative ionomic approach focusing on cadmium effects in sunflowers (Helianthus annuus $\mathrm{L}$ ). Environ Exp Bot 107:180-186

Kachur AV, Koch CJ, Biaglow JE (1998) Mechanism of copper-catalyzed oxidation of glutathione. Free Radic Res 28:259-269

Khan S, Rehman S, Khan A, Khan M, Shah M (2010) Soil and vegetables enrichment with heavy metals from geological sources in Gilgit, northern Pakistan. Ecotoxicol Environ Safety 73:1820-1827

Khan MIR, Nazir F, Asgher M, Per TS, Khan NA (2015) Selenium and sulfur influence ethylene formation and alleviate cadmium-induced oxidative stress by improving proline and glutathione production in wheat. J Plant Physiol 173:9-18

Khan A, Khan S, Alam M, Khan MA, Aamir M, Qamar Z, Rehman ZU, Perveen S (2016a) Toxic metal interactions affect the bioaccumulation and dietary intake of macro- and micro-nutrients. Chemosphere 146:121-128

Khan S, Munir S, Sajjad M, Li G (2016b) Urban park soil contamination by potentially harmful elements and human health risk in Peshawar City, Khyber Pakhtunkhwa, Pakistan. J Geochem Explor 165:102-110

Khan MA, Khan S, Khan A, Alam M (2017) Soil contamination with cadmium, consequences and remediation using organic amendments. Sci Total Environ 601-602:1591-1605

Kwak M-J, Jeong H, Madhaiyan M et al (2014) Genome information of Methylobacterium oryzae, a plant-probiotic methylotroph in the phyllosphere. PLOS ONE 9(9):e106704

Langmead B, Salzberg SL (2012) Fast gapped-read alignment with Bowtie-2. Nat Methods 9(4):357-359

Larkin MJ, Kulakov LA, Allen CC (2005) Biodegradation and Rhodococcusmasters of catabolic versatility. Curr Opin Biotechnol 16:282-290

Lee SW, Glickmann E, Cooksey DA (2001) Chromosomal locus for cadmium resistance in Pseudomonas putida consisting of a cadmium-transporting ATPase and a MerR family response regulator. Appl Environ Microbiol 67:1437-1444

Legatzki A, Grass G, Anton A, Rensing C, Nies DH (2003) Interplay of the Czc system and two P-type ATPases in conferring metal resistance to Ralstonia metallidurans. J Bacteriol 185:4354-4361

Li P-E, Lo C-C, Anderson JJ et al (2017) Enabling the democratization of the genomics revolution with a fully integrated web-based bioinformatics platform. Nucleic Acids Res 45(1):67-80

Lo C-C, Chain PSG (2014) Rapid evaluation and quality control of next generation sequencing data with FaQCs. BMC Bioinform 15:366

Lopez-Mill'a'n AF, Sagardoy R, Solanas M, Abadia A, Abadia J (2009) Cadmium toxicity in tomato (Lycopersicon esculentum) plants grown in hydroponics. Environ Exp Bot 65:376-385

Liu J, Zhang H, Zhang Y, Chai T (2013) Silicon attenuates cadmium toxicity in Solanum nigrum $\mathrm{L}$. by reducing cadmium uptake and oxidative stress. Plant Physiol Biochem 68:1-7

Madhaiyan M, Poonguzhali S, Sa T (2007) Characterization of 1-aminocyclopropane-1-carboxylate (ACC) deaminase containing Methylobacterium oryzae and interactions with auxins and ACC regulation of ethylene in canola (Brassica campestris). Planta 226(4):867-876

Marchler-Bauer A, Derbyshire MK, Gonzales NR et al (2015) CDD: NCBI's conserved domain database. Nucleic Acids Res 43(D):222-226

Marschner P (2012) Marschner's Mineral Nutrition of Higher Plants, 3rd edn. Academic Press, London

Mielke HW, Adams JL, Chaney RL, Mielke PW Jr, Ravikumar VC (1991) The pattern of cadmium in the environment of five Minnesota cities. Environ Geochem Health 13(1):29-34

Mohamed AA, Castagna A, Ranieri A, Sanita di Toppi L (2012) Cadmium tolerance in Brassica juncea roots and shoots is affected by antioxidant status and phytochelatin biosynthesis. Plant Physiol Biochem 57:15-22

Mongkolsuk S, Helmann JD (2002) Regulation of inducible peroxide stress responses. Mol Microbiol 45:9-15

Montecchia MS, Tosi M, Soria MA, Vogrig JA, Sydorenko O, Correa OS (2015) Pyrosequencing reveals changes in soil bacterial communities after conversion of Yungas forests to agriculture. PLoS ONE 10:e0119426. https ://doi.org/10.1371/journal.pone.0119426

Moynihan M, Peterson KE, Cantoral A et al (2017) Dietary predictors of urinary cadmium among pregnant women and children. Sci Total Environ 575:1255-1262
Nawab J, Khan S, Aamir M, Shamshad I, Qamar Z, Din I, Huang Q (2016) Organic amendments impact the availability of heavy metal(loid)s in mine-impacted soil and their phytoremediation by Penisitum americanum and Sorghum bicolor. Environ Sci Pollut Res 23(3):2381-2390

Nies DH (1992) CzcR and CzcD, gene products affecting regulation of resistance to cobalt, zinc, and cadmium (czc system) in Alcaligenes eutrophus. J Bacteriol 174:8102-8110

Nies DH (1995) The cobalt, zinc, and cadmium efflux system CzcABC from Alcaligenes eutrophus functions as a cation-proton antiporter in Escherichia coli. J Bacteriol 177:2707-2712

Nies D (1999) Microbial heavy-metal resistance. Appl Microbiol Biotechnol $51: 730-750$

Nies DH (2003) Efflux-mediated heavy metal resistance in prokaryotes. FEMS Microbiol Rev 27:313-339

Nies DH, Silver S (1989) Plasmid-determined inducible efflux is responsible for resistance to cadmium, zinc, and cobalt in Alcaligenes eutrophus. J Bacteriol 171:896-900

Nies DH, Nies A, Chu L, Silver S (1989) Expression and nucleotide sequence of a plasmid determined divalent cation efflux system from Alcaligenes eutrophus. Proc Natl Acad Sci USA 86:7351-7355

Noguchi H, Park J, Takagi T (2006) MetaGene: prokaryotic gene finding from environmental genome shotgun sequences. Nucleic Acids Res 34(19):5623-5630

Nucifora G, Chu L, Misra TK, Silver S (1989) Cadmium resistance from Staphylococcus aureus plasmid pl 258 cadA gene results from a cadmium efflux ATPase. Proc Natl Acad Sci USA 86:3544-3548

Oulas A, Pavloudi G, Polymanakou P, Pavlopoulus GA, Papanikolaou N, Kotoulas G, Arvanitidis C, lliopoulus I (2015) Metagenomics: tools and insights for analyzing next-generation sequencing data derived from biodiversity studies. Bioinform Biol Insights 9:75-88

Pal C, Bengtsson-Palme J, Rensing C, Kristiansson E, Larsson DG (2014) BacMet: antibacterial biocide and metal resistance genes database. Nucleic Acids Res 42(1):737-743

Peng Y, Leung HC, Yiu SM, Chin FY (2012) IDBA-UD: a de novo assembler for single-cell and metagenomic sequencing data with highly uneven depth. Bioinformatics 28(11):1420-1428

Rai PK, Lee SS, Zhang M, Tsang YF, Kim K-H (2019) Heavy metals in food crops: health risks, fate, mechanisms, and management. Environ Int 125:365-385

Rensing C, Mitra B, Rosen BP (1997) The zntA gene of Escherichia coli encodes a Zn(II)- translocating P-type ATPase. Proc Natl Acad Sci USA 94:14326-14331

Rensing C, Ghosh M, Rosen BP (1999) Families of soft-metal-ion-transporting ATPases. J Bacteriol 181:5891-5897

Rhee SK, Liu X, Wu L, Chong SC, Wan X, Zhou J (2004) Detection of genes involved in biodegradation and biotransformation in microbial communities by using 50 -mer oligonucleotide microarrays. Appl Environ Microbiol 70(7):4303-4317

Salam LB (2018) Detection of carbohydrate-active enzymes and genes in a spent engine oil-perturbed agricultural soil. Bull Natl Res Cent 42:10

Salam LB, Ishaq A (2019) Biostimulation potentials of corn steep liquor in enhanced hydrocarbon degradation in chronically polluted soil. Biotech 9:46

Salam LB, Obayori OS (2019) Structural and functional metagenomics analyses of a tropical agricultural soil. Spanish J Soil Sci 9(1):1-23

Salam LB, Obayori OS, Raji SA (2015) Biodegradation of used engine oil by a methylotrophic bacterium, Methylobacterium Mesophilicum isolated from tropical hydrocarbon-contaminated soil. Petrol Sci Technol 33(2):186-195

Salam LB, Obayori OS, Nwaokorie FO, Suleiman A, Mustapha R (2017) Metagenomic insights into effects of spent engine oil perturbation on the microbial community composition and function in a tropical agricultural soil. Environ Sci Pollut Res 24:7139-7159

Salam LB, Ilori MO, Amund OO, LiiMien Y, Nojiri H (2018) Characterization of bacterial community structure in a hydrocarbon-contaminated tropical African soil. Environ Technol 39(7):939-951

Salam LB, Shomope H, Ummi Z, Bukar F (2019) Mercury contamination imposes structural shift on the microbial community of an agricultural soil. Bull Natl Res Cent 43:163

Satarug S, Baker JR, Reilly PE, Moore MR, Williams DJ (2001) Changes in zinc and copper homeostasis in human livers and kidneys associated with exposure to environmental cadmium. Hum Exp Toxicol 20:205-213 
Scherer J, Nies DH (2009) CzcP is a novel efflux system contributing to transition metal resistance in Cupriavidus metallidurans $\mathrm{CH} 34$. Mol Microbiol 73:601-621

Schloss PD, Westcott SL, Ryabin T et al (2009) Introducing mothur: opensource, platform-independent, community-supported software for describing and comparing microbial communities. Appl Environ Microbiol 75(23):7537-7541

Steinnes E, Friedland AJ (2006) Metal contamination of natural surface soils from long-range atmospheric transport: existing and missing knowledge. Environ Rev 14:169-186

Stohs SJ, Bagchi D (1995) Oxidative mechanisms in the toxicity of metal-ions. Free Radic Biol Med 18:321-336

Stohs SJ, Bagchi D, Hassoun E, Bagchi M (2001) Oxidative mechanisms in the toxicity of metal ions. Free Radic Biol Med 18:321-336

Toppi LSD, Gabbrielli R (1999) Response to cadmium in higher plants. Environ Exp Bot 41(2):105-130

Törönen P, Medlar A, Holm L (2018) PANNZER2: a rapid functional annotation webserver. Nucleic Acids Res 46(W1):W84-W88

Trivedi P, Delgado-Baquerizo M, Anderson IC, Singh BK (2016) Response of soil properties and microbial communities to agriculture: implications for primary productivity and health indicators. Front Plant Sci 7:990

Valencia EY, Braz VS, Guzzo C, Marques MV (2013) Two RND proteins involved in heavy metal efflux in Caulobacter crescentus belong to separate clusters within proteobacteria. BMC Microbiol 13:79
Vallee BL, Ulmer DD (1972) Biochemical effects of mercury, cadmium and lead. Annu Rev Biochem 41:91-128

Waisberg M, Joseph P, Hale B, Beyersmann D (2003) Molecular and cellular mechanisms of cadmium carcinogenesis. Toxicol 192(2-3):95-117

WHO/FAO (2001). Codex alimentarius commission. Food additives and contaminants. Joint FAO/WHO Food Standards Programme, ALINORM 10/12A

Wood DE, Salzberg SL (2014) Kraken: ultrafast metagenomic sequence classification using exact alignments. Genome Biol 15(3):R46

Xiong A, Jayaswal RK (1998) Molecular characterization of a chromosomal determinant conferring resistance to zinc and cobalt ions in Staphylococcus aureus. J Bacteriol 180:4024-4029

Yazdankhah A, Moradi S, Amirmahmoodi S, Abbasian M, Shoja SE (2010) Enhanced sorption of cadmium ion on highly ordered nanoporous carbon by using different surfactant modification. Microporous Mesoporous Mater 133:45-53

Yin C, Mueth N, Hulbert S (2017) Bacterial community on wheat grown under long-term conventional tillage and no-till in the Pacific Northwest of the United States. Phytobiomes J 1(2):83-90

\section{Publisher's Note}

Springer Nature remains neutral with regard to jurisdictional claims in published maps and institutional affiliations.

\section{Submit your manuscript to a SpringerOpen ${ }^{\circ}$ journal and benefit from:}

- Convenient online submission

- Rigorous peer review

- Open access: articles freely available online

- High visibility within the field

- Retaining the copyright to your article

Submit your next manuscript at $\boldsymbol{\nabla}$ springeropen.com 